\title{
A MARKEDNESS ANALYSIS OF INITIAL CONSONANT CLUSTERS IN APHASIC PHONOLOGICAL IMPAIRMENT: A CASE STUDY.
}

\author{
LESLEY WOLK, B.A. (SP. \& H. TH.) (WITWATERSRAND) \\ Dept. Speech Therapy and Audiology, Baragwanath Hospital, Johannesburg.
}

\begin{abstract}
SUMMARY
The purpose of this study was to assess both the theoretical and clinical value of markedness theory in phonological impairment in aphasia. A markedness analysis was carried out on initial consonant clusters in a single aphasic adult, at two points during the spontaneous recovery phase. Results revealed systematic, rule-governed behaviour, reflecting similar linguistic trends, in terms of natural segments and natural processes, on both testing occasions. Some inadequacies of the distinctive feature approach are discussed. The findings of this study suggest that a markedness analysis may be extremely useful for the analysis and treatment of phonological disorders in aphasia.
\end{abstract}

\section{OPSOMMING}

Die doel van hierdie studie was om beide die teoretiese en kliniese waarde van die merkbaar* heids teorie ('markedness theory') in fonologiese gebrek in afasie te evalueer. 'n Merkbaarheids analise is uitgevoer op inisiële konsonant groepe in 'n enkele volwassene met afasie op twee tydstippe tydens die spontane herstel periode. Resultate het sistematiese reël-gebonde gedrag tydens albei toetsgeleenthede getoon, wat 'n soortgelyke taalpatroon weerspiec̈l het in terme van beide natuurlike segmente en prosesse. Sommige tekortkominge van die benadering van die onderskeidings kenmerke word bespreek. Die bevindings van hierdie studie toon aan dat ' $n$ merkbaarheids analise baie nuttig mag wees in die analise en behandeling van fonologiese abnormaliteite in afasie.

Central to the analysis and treatment of aphasic phonological impairment is the application of linguistics. Luria assumes the phoneme to be the basic unit of all spoken language. ${ }^{21}$ This statement encompasses two fundamental justifications for the study of phonology as discussed by Spreen, ${ }^{30}$ firstly for its own intrinsic value, and secondly as the presence of articulatory substitutions may interrupt the investigation and treatment of higher order linguistic events.

There are two major characteristics of aphasic phonological impairment; the substitution process in which the selection and substitution are two faces of the same operation, ${ }^{16}$ and the disruption of phonemic sequencing. Studies of articulatory difficulties in aphasia have dealt mainly with substitution phenomena, and have placed little emphasis on the combination process. In view of the fact that patients with articulation problems show particular difficulty in the production of consonant clusters, ${ }^{1,20,29}$ an in-depth investigation of this was felt to be an interesting medium through which these dimensions (selection and sequencing) could be explored. 
'Apraxia of Speech' is a term commonly used to describe articulation difficulties in aphasia. It is clearly differentiated in this study from oral apraxia, which is defined by DeRenzi and Vignolo ${ }^{8}$ as:

the inability to perform voluntary movements with the muscles of the larynx, pharynx, tongue, lips and cheeks; although automatic movements of the same muscles are preserved.

A basic controversy seems to emerge from the literature, reflecting two opposing views about articulation disorders in 'apraxia of speech.' Several studies $5,7,29$ reveal that articulation errors in 'apraxia of speech' are primarily inconsistent, reflecting a lack of systematic relationships between error and target sounds; while other writers ${ }^{1,9,13,16,33}$ have emphasized the systematic nature of articulation errors. Specific attention has been drawn to the possibility of applying distinctive - feature theory to phonemic errors in an aphasic adult. ${ }^{19}$ It seems that the distinctive feature (D.F.) approach may have certain inadequacies. While most researches in speech pathology have found a feature framework valuable as both a descriptive and therapeutic tool, ${ }^{25,}{ }^{31}$ it has come under attack by Walsh, ${ }^{34}$ Hyman ${ }^{14}$ and others, who feel that a D.F. approach has as its principle object an abstract, idealized level of language. It is primarily concerned with the system and structures of phonological oppositions rather than with concrete manifestations of human speech.

Recently, another linguistic theory has received attention in the exploration of children's phonological systems. This theory is called 'markedness Theory' (M.T.) based on the underlying theoretical assumptions of natural phonology proposed by David Stampe. ${ }^{6,14}$ While it has been claimed that the notion of markedness is highly relevant to the analysis of aphasic speech, in agreement with Kagan, ${ }^{19}$ the writer felt that it had not been placed in perspective linguistically.

The 'naturalness' of certain segments in phonological systems can be captured through the notion of 'markedness.' Two phonemes or phoneme sequences (segments) are differentiated by considering one of them unmarked (u) for a particular feature and the other marked (m) for that feature. The basic assumption is that the (u) member represents the more natural state, whereas the sum of the $(\mathrm{m})$ features represents the complexity of that phoneme. ${ }^{2,4}$ Relative complexity is derived from perceptual distinctiveness, frequency of occurrence of certain phonemes among languages of the world, and physiological considerations such as deviations of the vocal apparatus from a phonetically neutral position. ${ }^{2,24}$ Within the framework of natural phonology, it is assumed that the process of acquisition of the phonetic pattern of language, is therefore a process of inhibiting natural processes.

The underlying rationale for this study was to investigate whether an application of M.T. would firstly be of theoretical value in yielding a better understanding into speech processes resulting from neurological disruption, and secondly to assess its clinical use. 


\section{METHOD}

\section{SUBJECT (S)}

The $\mathrm{S}$ used in this study was a white, South African, English-speaking adult male, aged 56 years. Severe expressive aphasia resulted from an intracerebral haemorrhage in the distribution of the middle cerebral artery, which was further confirmed by an EMI scan. The S selected fulfilled the following criteria:

1) He was diagnosed as aphasic by a neurologist and a speech therapist, and was assessed as having 'apraxia of speech' (as defined by Deal and Darley $\left.{ }^{7}\right)$. This was further confirmed by a formal rating on the Boston Diagnostic Test of Aphasia. ${ }^{12}$

2) The $S$ demonstrated articulation difficulties, particularly on consonant clusters.

3) Dysarthria was ruled out as being etiologically related to the articulation difficulties.

4) Oro-facial apraxia was ruled out as being causally related to the articulatory errors.

5) Peripheral hearing and vision were within normal limits.

6) The S's mother tongue was English.

7) The $S$ had an adequate premorbid acquisition of speech and language.

AIMS

1) To determine whether articulation errors on initial-stem consonant clusters in a single case of aphasia, can be characterized by systematic, rule-governed behaviour.

2) To assess the applicability of markedness theory to phonological impairment in an aphasic in terms of the following:-

a) Are unmarked (u) phonemes and phoneme sequences substituted for marked $(\mathrm{m})$ ones more than the reverse?

b) Do successive attempts at self-correction reveal a progression towards the target segment in terms of complexity values $(\mathbf{u}-\cdot \mathbf{m})$, or are they random?

c) Are predictable patterns set up in one testing confirmed by another?

d) Can articulation errors be characterized by natural phonological processes?

3) To discuss the appropriateness of the term 'apraxia of speech' used to describe phonological impairment in aphasia, with reference to the general findings and two further issues:-

i) Whether 'apraxia of speech' is purely a motor disorder, or whether there is a sensory component.

ii) Whether 'apraxia of speech' is purely an articulatory disorder or whether there is an inter-action with other levels of language function. 


\section{TESTS AND PROCEDURE}

Pre-tests

1) The Boston Diagnostic Aphasia Examination. ${ }^{12}$

This test was used in order to obtain a profile of scores on various linguistic dimensions. Administration followed the procedures laid down in the test manual.

2) A screening Pure-Tone Audiometric Test.

This test was administered at a reference threshold level of $15 \mathrm{~dB}$ (ISO 1964). The $S$ responded adequately at all frequencies, indicating that hearing was within normal limits.

3) A neurological Examination.

A detailed battery of neurological tests were carried out by a neurologist, which served to satisfy those criteria not assessed on the Boston Examination and to further confirm others.

4) Auditory Discrimination Tests.

a) The Goldman-Fristoe Test of Auditory Discrimination."

This test was administered in order to assess the S's competence for discriminating between single consonants. Administration procedures followed those laid down in the test manual.

b). In order to evaluate the S's ability to recognize cluster versus noncluster segments, an informal test of 50 minimal pair words was devised (eg. tea/tree).

5) Auditory memory span.

An informal test of auditory memory span was administered using (a) a series of digits, (b) a series of related words and (c) a series of unrelated words. This was felt to be a crucial aspect in the consideration of consonant cluster production.

6) The Goldman-Fristoe Test of Articulation. ${ }^{10}$

Part of this test was administered in order to assess basic trends occurring on single consonants within the context of meaningful words. This was felt to provide a basis for the analysis of consonant clusters.

Tests

Two approaches were used for elicitation of speech for linguistic analysis:

a) Controlled elicitation through naming (Naming Task.),

b) Uncontrolled elicitation through the collection of spontaneous speech (Spontaneous Tasks.)

a) Naming Task

While many articulation tests are available, none have been designed for in-depth phonological analysis of consonant clusters.

A task was thus devised, comprising 106 stimulus cards representing words with initial-stem consonant cluster sequences. Stimulus cards consisted of large coloured pictures mounted on white cards. The words 
to be elicited were written on the back of each card for the purpose of the tester.

Criteria for selection of words:

28 Initial-stem consonant clusters in English are listed. ${ }^{18}$ Each one was elicited in more than one stimulus word, ranging between two and six different phonemic environments. The environment was varied with respect to both vowels and consonants in the immediate phonemic vicinity. An attempt was made to take into account word length and syllable structure in devising the test items.

Experimental manipulation of words:

Stimulus pictures were restricted by the following constraints i) phonological rules governing the combination and sequencing of phonemes in English, and ii) those words which could be pictorially represented, for the reason that the use of imitation was deliberately avoided so as to prevent contamination of results by providing a model. In addition, an informal test of 20 words comprising final-stem consonant clusters was devised. They were divided in to two groups of 10 each. In the first group, the consonant clusters were purely phonological constructions (PC) such as /sp/ in "lisp". In the second group, the final consonant clusters were morphological combinations such as /st/ in "crossed" or /ts/ in "pots". CVCC words were restricted to combinations of $/ s /+$ voiceless plosive (sp, st, sk) or (ps, ts, ks), as these are the only two elements comprising a final-stem cluster which occur in both (PC) and (MC). Each word was tested in two to three different phonemic environments. This test was included so as to assess superficially whether any other subtle linguistic deficits were operating apart from a phonological impairment.

Rationale for use of meaningful words:

Meaningful words were used as opposed to nonsense syllables, for the reasons that firstly in all speaking situations, sound and meaning are inseparable and phonological errors are thus necessarily interactive with both semantic and syntactic levels of speech. Secondly, by observing errors in meaningful words, interesting phenomena such as assimilations and reversals within words and over word boundaries become obvious, and act as potential cues, for both diagnosis and treatment. Furthermore, the idea which permeates throughout this study, is that of naturalness, and nonsense syllables are in themselves an artificial form of speech.

b) Spontaneous Tasks

i) Thirty minutes of an open-ended conversation was elicited, concerning the patient's illness, work and general issues.

ii) Three Thematic Apperception Test (TAT) cards were used (numbers 1, 2, 13B) in order to elicit a spontaneous story.

iii) Six large coloured picture cards were carefully chosen in order to elicit several words with initial consonant clusters, within the context of connected speech. 
In addition, much of the spontaneous samples resulted from the $S$ 's misnaming of test items and interjected spontaneous speech. It was felt, that many previous studies in 'apraxia of speech' could be criticized for their use of nonsense syllable repetition tasks and specific naming tasks, thus failing to stimulate communicative language.

\section{ADMINISTRATION OF TEST PROCEDURES:-}

Two testing sessions took place with a six week interval between them. Testing A was carried out six weeks post-stroke, and Testing B was carried out three months post-stroke, which was considered to have taken place at a point of neurological stability. ${ }^{28}$ The second testing served (a) to assess improvement of articulatory performance during the period of spontaneous recovery; (b) to confirm phonological patterns set up in the first testing; and (c) to control for chance factors.

For the naming tasks, the $S$ was instructed to name the pictures on presentation of each card. They were presented in a random order, but attempts were made not to present two words with the same consonant cluster successively. Stimulus words with final-stem consonant clusters were elicited in a similar manner. For the spontaneous tasks, the $S$ was instructed to tell a story with a beginning, a middle and an end in response to each individual TAT test card, and to describe each of the six test picture cards discussed above. Testings took place at different times of the day, so as to obtain a representative sample of performance. They were carried out for short periods of time ( $30-40$ minutes per session) which enabled the tester to control as far as possible for variables such as fatigue, anxiety, motivation, mood and other external factors. In Testing $\mathrm{B}$, the following pre-tests were re-administered: The Goldman-Fristoe test of Auditory Discrimination" and Production, ${ }^{10}$ and the Boston Diagnostic Aphasia Examination. ${ }^{12}$

\section{Analysis Procedure and Scoring:}

All responses were recorded on a Revox Tape Recorder (model 1132 Dolby version). Responses were transcribed in broad phonetic transcriptions at the time of testing where possible, and later by several transcribers, thus providing maximum objectivity and accuracy of recorded data.

The Analysis procedure was carried out along the following dimensions:-

1. a) A frequency count of correct versus incorrect résponses. One point was assigned for the correct production of the cluster on initial attempt. Half a point was assigned for the correct production on one of the subsequent attempts, and 0 for the incorrect production ie. where the target was never reached. All points were totalled for each cluster in proportion to the total number $(\mathrm{N})$ of test words for that cluster (which varied according to the number of self-corrections). A percentage was calculated for the total number of correct responses out of the total number of stimulus test words. 
(Note: Both Testing A and B comprised 106 test items each on naming tasks; whereas the criterion for spontaneous tasks, was to extract from the total spontaneous speech sample, between 100 106 initial-stem consonant cluster words in order to confirm the findings on the more structured tasks).

b) A Distribution of errors according to Omissions (O), Substitutions (S), Additions (A) and Distortions (D). In C1C2VC syllable structures, it is obvious that one or more of the 4 error categories may occur concurrently in one word.

c) A subphonemic feature analysis of substitution errors according to the features of place $(\mathrm{P})$, manner $(\mathrm{M})$, voice $(\mathrm{V})$. Overlapping categories were developed so as to accommodate substitutions which were defective in two or more features. (P-M, P-V, M-V, P. $\mathrm{M}-\mathrm{V})$. This method is suggested by La Pointe and Johns. ${ }^{20}$

2. A Markedness Analysis

a) Articulation errors on initial consonant clusters were subjected to a markedness analysis by applying marked (m) and unmarked (u) values to every consonant and total complexity values to every consonant cluster sequence.

b) The $\mathrm{m} / \mathrm{u}$ table, devised by the writer, was based on those values suggested by Cairns, ${ }^{2}$ Chomsky and $\mathrm{Halle}^{4}$ with various modifications. (see Table I).

c) A 9-Distinctive Feature (D.F.) matrix was used with values available for the following features: consonantal, sonorant, anterior, coronal, continuant, strident, voice, lateral and nasal. A complexity score was computed by adding the (m) features in each consonant.

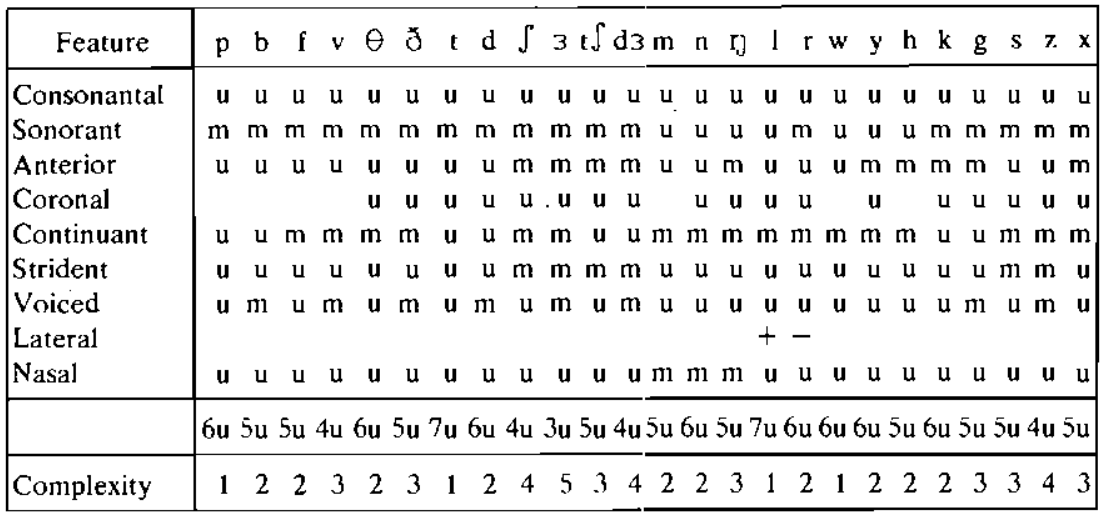

Note: Although / $\mathbf{X}$ / is not an English phoneme, it is included in the Table as the $\mathrm{S}$ used this sound in his speech.

TABLE. I: $\mathrm{m} / \mathrm{u}$ Values for all Consonants in English, using a 9 Distinctivefeature matrix. 
d) The analysis of individual feature change can, therefore, assume one of the following possible patterns $\mathrm{m} \rightarrow \mathrm{u}, \mathrm{m} \rightarrow \mathrm{m}, \mathrm{u} \rightarrow \mathrm{u}$, $\mathrm{u} \cdots \mathrm{m}$.

e) The symbols $(\mathrm{m}),(\mathrm{u})$ and $(\mathrm{mm})$ were used to refer to the direction of change in terms of complexity values:

(m) - The target cluster, or a substitution of equal complexity value to that of the target.

(u) - A substituted phoneme or phoneme sequence which has a lower complexity value than that of the target.

$(\mathrm{mm})$ - A substituted phoneme or phoneme sequence which has a greater complexity value than that of the target, which is always $(\mathrm{m})$; it reflects a change from less complex to more complex.

(note: the reason for assigning $(\mathrm{m})$ values to all target segments is that the CCVC words are already complex in terms of syllable structure.)

f) Phonological processes of simplification include a more detailed analysis of errors in the following categories: I syllable structure, II Environment, III Substitutions. (See Table VI).

SCORING: Model for assigning complexity values.

1) Paradigmatic values refer to a discrete value for each phoneme, depending on the sum total of $(\mathrm{m})$ features for each consonant. In this model, $V=0, C=$ Range between 1 and 5 , where $P=1,3=5$; thus reflecting the 'naturalness' of phonemes relative to articulatory and perceptual complexity.

2) Syntagmatic values refer to complexity values assigned according to the syllable structure of a word (or phonemic sequencing) such that $\mathrm{CV}=(+0)$

$\mathrm{C} 1 \mathrm{C} 2 \mathrm{~V}=(+\mathrm{i})$

$\mathrm{ClC} 2 \mathrm{C} 3 \mathrm{~V}=(+2)$

These values are justified in terms of the 'naturalness' of syllable structure. Syntagmatic values were applied to all consonant sequences, with the following implications - one of the most common neutralization rules governing consonant sequences in English, is that involving the /s/ phoneme. A feature is said to be 'neutralized' in an environment if the value of the feature in this environment is determined by a sequential restraint. ${ }^{32}$ A. Neutralization Rule (N-Rule) thus specifies that a particular feature or set of features may not have a (m) value in a given environment; ie the complexity value is reduced. In this model, a value of $(-2)$ is thus subtracted from the total complexity value, if $/ \mathrm{s} /$ occurs in the following environments:

a) In a $\mathrm{C} 1 \mathrm{C} 2$ cluster, where $\mathrm{C} 2$ 'varies with a voiceless plosive,

b) In $\mathrm{C} 1 \mathrm{C} 2 \mathrm{C} 3$ cluster, where $1 / \mathrm{s} /$ is the only phoneme which may occur in position $\mathrm{C} 1$, according to the rules of phonemic sequencing in English. 
(The value -2 was fairly arbitrarily chosen. Often an N-Rule would require a subtraction of the entire value; however, in this case /s/ has a value of 3 so that it would result in a value of 0 which is equal to a vowel in this model. For this reason, only a value of 2 was subtracted).

3) Complexity of cluster segments refer to values assigned according to the acquisition of consonant clusters. A definite sequence of acquisition for each cluster has not been given in the literature, as has been done for singletons. However values were based on the broad order of acquisition described by Ingram. ${ }^{15}$

These were divided into 3 groups:-

i) those acquired by age 4 years $(+0)$

ii) those acquired between ages $4-6$ years $(+1)$

iii) those acquired by age 7 years $(+2)$

Justification: One of the criteria used for assigning $(\mathrm{m})$ values to single consonants, is according to acquisition order. ${ }^{2,14}$ It was thus felt necessary to extend this to consonant clusters. All utterances were thus analyzed by applying all three rules. No. 1 describes complexity of single consonants or singletons; No. 2 refers to the complexity of syllable structure; and No. 3 describes complexity of consonant clusters.

Note: Consonant sequences produced by the $S$, which were 'nonEnglish' sequences, followed rules (1) and (2) but not (3).

The identical analysis procedures were applied to the data obtained in Testing $\mathrm{A}$ and Testing $\mathrm{B}$.

\begin{tabular}{|c|c|c|c|c|c|}
\hline & $\mathrm{r}$-blends & 1-blends & s-blends & $\begin{array}{c}\text { 2-element } \\
\text { blends }\end{array}$ & 3-elenent blends \\
\hline Cluster & pr br tr dr kr gr fr $\theta r j r$ & pl bl kl gl fl & sm sn sp st sk sl sw & tw kw & spl spr str skr skw \\
\hline $\begin{array}{l}\text { Complexity } \\
\text { Value }\end{array}$ & $\begin{array}{lllllllll}4 & 5 & 4 & 5 & 5 & 7 & 6 & 7 & 9\end{array}$ & $\begin{array}{lllll}3 & 4 & 4 & 5 & 5\end{array}$ & $\begin{array}{lllllll}4 & 4 & 3 & 3 & 4 & 7 & 7\end{array}$ & 34 & $\begin{array}{lllll}7 & 8 & 7 & 9 & 7\end{array}$ \\
\hline
\end{tabular}

TABLE I I: A list of complexity values for each initial-stem consonant cluster in English.

\section{RESULTS AND DISCUSSION}

(i) The Boston Diagnostic Aphasia Examination:-

The S obtained overall scores of (2) and (3) on Testing A and Testing B respectively, according to Goodglass and Kaplan's categories. ${ }^{12}$ The profile of scores thus served to reflect the interactions of various deficits at a given time, and the improvement from one point in recovery to another.

(ii) The $\mathrm{S}$ made no errors on traditional tests of auditory discrimination.

1. a) Frequency Count:

Analysis of correct versus incorrect responses, revealed an improvement on consonant cluster production during the period of spontaneous recovery. For example, a score of $51,42 \%$ was 
obtained on the naming task in Testing $\mathrm{A}$, and $65,56 \%$ on the naming task on Testing $\mathbf{B}$.

1. b) Analysis of omissions (O), substitutions, (S), additions (A) and distortions (D):

Results clearly illustrated the predominance of (S) errors, followed by $(\mathrm{O})$. (A) and (D) comprised the smaller part of the contribution to the total number of errors. The frequency of errors followed the sequence $S>O>D>A$ which was consistent on all tasks. The fact that patients with 'apraxia of speech' make more errors in substitutions is well supported in the literature. ${ }^{1,33}$

1. c) Subphonemic Feature Analysis:

On all tasks, results revealed that errors of place ( $p$ ) comprised the largest percentage $(\%)$, followed by errors of manner $(\mathrm{m})$ and a combination of these ( $\mathrm{p}-\mathrm{m})$. Errors of voice $(v)$ either alone or in combination with others comprised the smaller parts. These results were consistent with the literature. ${ }^{20,33} \mathrm{It}$ is interesting that the frequency of errors in children is also seen as $P>M>V$.

2. a) Markedness Analysis:

A separate 9-D.F. matrix was drawn up for each target consonant cluster and its various substitutions; for the naming and spontaneous tasks on both Testing A and Testing B. Marked (m) and unmarked $(\mathrm{u})$ values were assigned to each consonant in the matrix (transposed from Table I). The total number of $m$ 's were added so as to reveal the complexity value of each consonant on the paradigmatic axis. By applying the 'rules' discussed in analysis procedure, total complexity values were assigned to each cluster sequence, thus incorporating both paradigmatic and syntagmatic levels.

A markedness analysis of all errors revealed that many of the utterances consisted of phonemes and phoneme sequences in which the value of the features in the target segments were retained $(\mathrm{m})$. When a change occurred, most of the target segments were replaced by (u) segments and only a few were replaced by $(\mathrm{mm})$ segments. For example, in naming $\mathrm{A}$, out of a total of 285 utterances, $128(44,92 \%)$ were replaced by (u) segments, and only $49(17,19 \%)$ were replaced by (mm) segments.

The remainder revealed no change $(\mathrm{m})$. Clearly the data did not support a statement that the S's articulation errors always reflect a change from more to less complex. However, they did suggest that when a change occurs, it is more likely that the direction will be from more to less complex (m, u). A number of suggestions were made to explain those occasions where $(\mathrm{mm})$ segments replaced (m) segments, such as assimilations, slips of the tongue, or. complexity over the entire word. 
$\operatorname{sm}(3-2)+2+1=(4)$

\begin{tabular}{|l||l|l||l|l|l|}
\hline \multicolumn{1}{|c||}{ Feature } & s & m & s & p & m \\
\hline Cons & u & u & u & u & u \\
Son & m & u & m & m & u \\
Ant & u & u & u & u & u \\
Cor & u & & u & & \\
Cont & m & m & m & u & m \\
Stri & m & u & m & u & u \\
Voice & u & u & u & u & u \\
Lat & & & & & \\
Nas & u & m & u & u & m \\
\hline Complexity & 3 & 2 & 3 & 1 & 2 \\
\hline
\end{tabular}

Total Complexity

\begin{tabular}{|l|c|c|c|}
\hline Word & Cluster & Total C & $\mathrm{m} / \mathrm{u}$ \\
\hline 1 smell & $\mathrm{m}$ & 2 & $\mathrm{u}$ \\
& $\mathrm{sm}$ & 4 & $\mathrm{~m}$ \\
$\mathbf{4}$ smar- & $\mathrm{m}$ & 2 & $\mathrm{u}$ \\
ties & $\mathrm{sp}$ & 3 & $\mathrm{u}$ \\
3 smiling & $\mathrm{sp}$ & 3 & $\mathrm{u}$ \\
& $\mathrm{sp} \rightarrow \mathrm{m}$ & 3 & $\mathrm{u}$ \\
4 smoke & $\mathrm{sm}$ & 4 & $\mathrm{~m}$ \\
\hline
\end{tabular}
Total C $=$ Total Complexity
$\mathrm{m} / \mathrm{u} \quad=$ Marked or Unmarked segments.

TABLE III : Example of a 9 D.F. matrix computed for the initial consonant cluster $/ \mathrm{sm} /$, and its various substitutions.

From Table III it can be seen that there is a tendency for (u) segments to replace $(m)$ ones, which is consistent with Blumstein ${ }^{1}$ and Kagan's ${ }^{19}$ findings. It should be noted that Kagan dealt primarily with singletons, Blumstein with consonant clusters on syllable structure only, and neither provided a detailed account of relative complexity values. It thus makes it difficult to incorporate their findings in the discussion of the present data. Cairns ${ }^{3}$ found that the child's substitutions may be characterized by a shift towards the $(\mathrm{u})$ value for a particular feature. She felt that the $\mathrm{m} / \mathrm{u}$ values of features are of more value in accounting for substitutions, than only the $t /-$ dimension.

2. b) Analysis of Self-Correction:

Results indicate that there was a stronger tendency for a progression to occur, rather than a nonprogression. ie. As the $S$ approximated the target segment, he substituted phonemes or phoneme sequences of increasing complexity. Not only do results on spontaneous tasks confirm those on naming tasks, but also results on Testing $\mathbf{B}$ revealed that the tendency for a progression in terms of complexity values to occur, becomes more firmly established towards the end of spontaneous recovery.

The example 'scratch' in Table IV clearly demonstrates the process of self-correction for the cluster $/ \mathrm{skr} /$. The initial attempt is a single consonant $/ 1 /$ with a low complexity value equal to 1 , reflecting the most natural syllable structure CVC. The second and third attempts are consonant clusters $/ \mathrm{kl} /$ and $/ \mathrm{sl} /$ respectively with complexity values of 4 and 7 respectively. On the fourth attempt, the target segment is reached, namely the most complex syllable structure $\mathrm{C} 1 \mathrm{C} 2 \mathrm{C} 3 \mathrm{VC}$ where $/ \mathrm{skr} / \mathrm{has}$ a total complexity value equal to 9 .

Johns and Darley ${ }^{17}$ characterize the 'variability' of phonemic production in 'apraxia of speech,' as unrelated, additive, substitutions, repetitions and blocks, groping through repeated efforts towards the correct production. This finding contradicts that of the present study, which provides evidence for a pattern of successive attempts at self-correction 
$\operatorname{skr}(3-2)+(2+2)+2+2=(9)$

\begin{tabular}{|l||l|l|l||l|l|l||l|l|}
\hline Feature & s & k & r & I & k & I & s & I \\
\hline Cons & u & u & u & u & u & u & u & u \\
Son & m & m & m & u & m & u & m & u \\
Ant & u & m & u & u & m & u & u & u \\
Cor & u & u & u & u & u & u & u & u \\
Cont & m & u & m & m & u & m & m & m \\
Stri & m & u & u & u & u & u & m & u \\
Voice & u & u & u & u & u & u & u & u \\
Lat & & & - & + & & + & & + \\
Nas & u & u & u & u & u & u & u & u \\
\hline Compl. & 3 & 2 & 2 & l & 2 & I & 3 & I \\
\hline
\end{tabular}

Total Complexity

\begin{tabular}{|c|c|c|c|}
\hline Word & Cluster & Tota & $\mathrm{m} / \mathrm{u}$ \\
\hline Scratch & $\begin{array}{r}\mathrm{l} \\
\mathrm{kl} \\
\mathrm{sl} \\
\mathrm{skr}\end{array}$ & $\begin{array}{l}1 \\
4 \\
7 \\
9\end{array}$ & $\left(\begin{array}{l}u \\
u \\
u \\
m\end{array}\right)_{u \rightarrow m}$ \\
\hline
\end{tabular}

TABLE IV: Example of a 9 D.F. matrix computed for the initial-stem consonant cluster $/ \mathrm{skr} /$, to show the process of self-correction.

with a definite link or 'relatedness' between error production and desired production.

These results were felt to be extremely significant for two reasons: Firstly it provided an opportunity to observe dynamic linguistic processing, and secondly it provided further information about perception. The fact that the $S$ was able to monitor his own productions showed that to some extent the perceptual mechanism is functioning. However, that this process of selfcorrection was somewhat less than perfect, resulting in further substitution errors seemed to point to a subtle deficit in the sensori-motor feedback loop. The interesting phenomenon which seems to arise is that there is a discrepancy between performance on a purely perceptual task and performance on a task involving an interaction between perception and production. The implications of this were felt to go beyond the scope of this study. However, it may be a worthwhile point for future investigation, which might provide further insight into theories of speech perception and production.

$$
\operatorname{pr}(1+2)+1
$$

(4) Total Complexity

\begin{tabular}{|c|c|c|c||c|c|c|}
\hline \multirow{2}{*}{ Word } & \multicolumn{3}{|c||}{ Testing A } & \multicolumn{3}{c|}{ Testing B } \\
\cline { 2 - 7 } 1 prize & Cluster & Total C & $\mathrm{m} / \mathrm{u}$ & Cluster & Total C & $\mathrm{m} / \mathrm{u}$ \\
\cline { 2 - 7 } & $\mathrm{p}$ & 1 & $\mathrm{u}$ & $\mathrm{pl}$ & 3 & $\mathrm{u}$ \\
& $\mathrm{f}$ & 2 & $\mathrm{u}$ & $\mathrm{pr}$ & 4, & $\mathrm{~m}$ \\
& $\mathrm{pl}$ & 3 & $\mathrm{u}$ & & & \\
& $\mathrm{pr}$ & 4 & $\mathrm{~m}$ & & & \\
\hline 2 pram & $\mathrm{pl}$ & 3 & $\mathrm{u}$ & $\mathrm{pl}$ & 3 & $\mathrm{u}$ \\
& & & & $\mathrm{pr}$ & 4 & $\mathrm{~m}$ \\
\hline 3 present & $\mathrm{pr}$ & 4 & $\mathrm{~m}$ & $\mathrm{pr}$ & 4 & $\mathrm{~m}$ \\
\hline
\end{tabular}

TABLE V: An Example of cluster /pr/ from naming task A and naming task B, to show the predictable course of recovery. 
Table $\mathrm{V}$ provides an illustration of the predictable patterns set up in Testing A which are confirmed in Testing B. The same progression occurred on both testings ie. $u \rightarrow m$, and fewer attempts were required in Testing $\mathrm{B}$, before reaching the target segments. For example, in the word 'prize', there were four attempts towards the target segment in Testing A ranging from $/ \mathrm{p} /-(1)$ to $/ \mathrm{pr} /-(4)$. Assuming the pattern to be a range from $1-4$ in terms of complexity, one could predict a substitution of a phoneme or phoneme sequence comprising these phonemes, of values $2-4$, as approximations before reaching the target segment. In Testing B the first approximation was /p1/ with a complexity value of 3 , after which the target cluster /pr/ was reached.

This finding seems to have relevance for assessment and as a therapeutic aid. The ability to predict the outcome of each phonetic process is pointed out as another important difference between Jakobson and Stampe's theories. Jakobson's ${ }^{16}$ account of D.F. theory has a universal hierarchy of features arranged in a strict pattern of successive branchings, which are viewed as relative properties of a phoneme, defined within a network of oppositions. By contrast, Stampe ${ }^{6,14}$ sees a dynamic system consisting of these innate rules of natural processes, rather than a static hierarchy. From an informal analysis, similar trends were noted on singletons, in initial, medial and final positions, which provided further confirmation for results above. An observation of the data showed that similar error trends tended to occur on different clusters comprising the same elements. For example, in the clusters sp, pr, spr, the following substitutions were noted to occur in Testings $A$ and $B: b / s p, b r / s p r, f / s p$, $\mathrm{f} / \mathrm{pr}, \mathrm{pl} / \mathrm{pr}, \mathrm{spl} / \mathrm{spr}$. These results thus served to validate and confirm the findings on initial-stem consonant clusters and further suggested that some underlying system of internalized rules might be governing articulation errors.

\section{Some General Points:}

i) The $S$ was seen to correctly produce more of those clusters acquired earlier in normal child development than those of later acquisition. Results also corresponded with children's progress from $\mathbf{u} \rightarrow \mathbf{m}$ in their learning process.

ii) It is interesting to note than when the $S$ was struggling to produce a particular cluster, he frequently used several self-devices to aid the production. For example, to spell the word out aloud which was seen to facilitate correct production immediately, or to spontaneously incorporate the stimulus word in a sentence ie. an attempt to produce it in natural running speech.

iii) Several error productions could be interpreted as having semantic confusions, yet are fully explicable on a phonological level, eg. 'kribs' for twins, 'god' for dog, 'grub' for mug and 'breast' for dressed.

2. c) Analysis of Errors According to Natural Phonological Processes The major processes were subdivided into fourteen categories, thus extending those used by Blumstein' and Hatfield. ${ }^{13}$ Table VI 
represents a summary of all natural phonological processes, with a few examples from the raw data, to illustrate the type of errors produced on CVC and CCVC words. The findings indicate that certain processes seemed to occur more frequently than others in naming and spontaneous tasks on both Testings $\mathrm{A}$ and $\mathrm{B}$.

i) Syllable Structure: Cluster reduction occurred most frequently, representing a form of simplification $=\mathrm{CCVC} \rightarrow \mathrm{CVC}$.

ii) Environment:

There was a general tendency for regressive assimilations (R.A.) to occur more frequently than progressive assimilations (P.A.) on all tasks.

Metatheses were less common, but when they did occur, reversals of syllables occurred more often than reversals of phonemes. This finding may be interpreted in terms of M.T, in that such rules of consonant harmony increase the redundancy of the articulatory instruction of the word so that 'gog' would be easier than 'dog': 6, 32

iii) Substitutions:

The processes of fronting $(F)$ and stopping $(S)$ were clearly the most frequent where $F>S$. Many utterances were seen to include an overlap of stopping (plosivization) and fronting within the same segment. It would appear that while $(\mathbf{F})$ is more common, there is a marked tendency to substitute velar sounds, particularly the voiceless plosive $/ \mathrm{k} /$. This is consistent with Hatfield ${ }^{13}$ who reports some interchangeability between $/ t /$ and $/ \mathrm{k} /$ in both singletons and clusters.

Generally, the above findings are well supported in the literature on aphasic phonological impairment. ${ }^{1,13}$ From a brief comparison with phonological acquisition in the child, similar linguistic trends were seen to occur. Apart from the consistent findings of cluster reduction, ${ }^{15,26}$ other processes of syllable simplification have been found to occur in the child ie. Syllable Closure ( $\mathrm{CV}-, \mathrm{CVC}$ ), and the insertion of an epenthetic schwa thus splitting the cluster (C1C2-, CVC). ${ }^{15}$

Environmental errors, such as metatheses and assimilations, where regressive assimilation was greater than progressive assimilation were found to occur in the child. ${ }^{15,26}$ The various substitution processes found to operate in the $S$, are also reported to occur in the child, such as: fronting, stopping, denasalization, gliding, frication, nasal and velar substitutions. ${ }^{15}$ Overall results of $2 a, b, c$, d indicate that the general trends occurred on both natural segments and natural processes. Stampe discusses the repeated use of strategies or natural phonological processes in the child. Its importance would seem to be the fact that it is the first theory to account for both the learning of the phonetic repertoire and of phonological relations. ${ }^{14}$ 


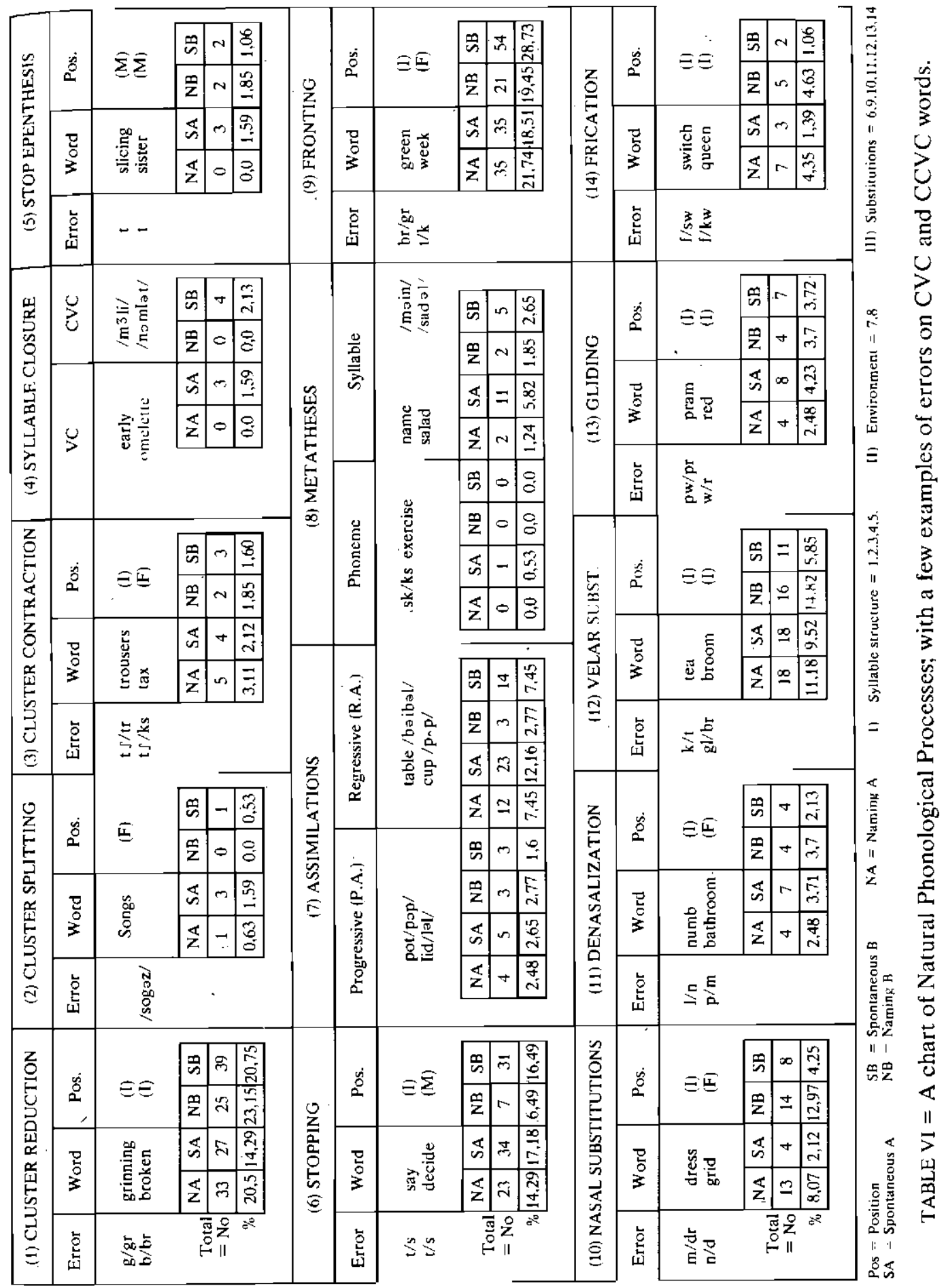

Die Suid-Afrikaanse Tydskrif vir Kommunikasieafwykings, Vol. 25, 1978 
In an attempt to assess the appropriateness of the term 'apraxia of speech', the following 2 sub-tasks were carried out.

3. i) A test of oral stereognosis

An abbreviated test of oral stereognosis comprising ten test items was carried out on the aphasic $S$ and 3 normal control subjects (C) matched for age, sex and educational level. Each test item (a threedimensional shape attached to a wand) was presented orally to the subjects, who were then required to match the shapes with a corresponding visual diagram. One point was awarded for each correct identification. The maximum score was thus ten points, which was then converted to a percentage. Results revealed that the aphasic $\mathrm{S}$ scored considerably lower than did the $\mathrm{C}$ subjects. (C1C2C3 all scored $100 \%$, while S scored $60 \%$ ).

This finding seems to suggest a subtle deficit in oro-sensory abilities in this aphasic adult; which is consistent with previous literature. ${ }^{27}$ It serves to revise the previous concept of a strictly motor disorder in 'apraxia of speech' and further suggests the incorporation of the kinesthetic modality in therapy.

3. ii) Naming task of final consonant cluster words of phonological (PC) and morphological construction (MC)

Findings revealed that the $S$ produced more words with (PC) clusters correctly than those with (MC) clusters. This would seem to indicate that more difficulty was experienced on final stem consonant clusters (CVCC) when there is a morphological (inflectional) ending superimposed on a phonological construction. These results are supported by Martin, Wasserman, Gildman, Gerstmenn and West ${ }^{23}$ who found that more errors occur on (MC) rather than (PC) final consonant clusters. Martin et al ${ }^{2.3}$ make the point that if 'apraxia of speech' was confined to a purely articulatory disorder, words involving an (MC) cluster, should have no effect on production. Martin ${ }^{22}$ states conclusively that: ... the concept of an apraxia of speech is a reflection of an outdated dichotomous model of language functioning that obscures the complex interactions involved in normal and aphasic language. No conclusive remarks, however, can be drawn from the small sample of words tested. It may only serve as an example indicating that this might be the case. Further research into the overlapping phonological and morphological constructions of final consonant clusters, might provide useful information about the interdependence of language functions in the adult aphasic.

\section{GENERAL DISCUSSION AND CONCLUSION}

An integration of all results revealed that

1) (u) Segments tended to replace (m) segments.

2) Successive attempts at self-correction showed approximations towards the target segment $(u \rightarrow m)$. 
3) Articulation errors could be characterized by natural phonological processes.

4) Trends observed in Testing A were confirmed in Testing B, and those occurring on naming tasks were confirmed on spontaneous tasks. ie. predictable patterns set up in one testing were confirmed by another. Slight variability, which was seen to occur within strict linguistic classes, was noted. Evidence thus seems to point to an organized 'system', less variable than a random set of articulation disorders.

The appropriateness of the term 'apraxia of speech' was questioned in view of the following three conclusions:

a) that errors could be characterized linguistically.

b) that rather than a purely motor disorder, there might be a mild orosensory perceptual component

c) the possibility of subtle levels of language breakdown on a morphological level, operating together with the phonological impairment.

It would thus appear to be a condition inseparable from the general aphasic disorder, and should be both assessed and treated in the light of the total syndrome.

Overall results seem to demonstrate the applicability of natural phonology (NP) to phonological impairment in aphasia. The apparent bias of N.P. is clearly that of 'production'. The perceptual data in the present study are not adequately dealt with in the conceptual framework of N.P., which places certain limitations on its general use. However, it is felt that in conjunction with other approaches, M.T. may be highly applicable to aphasia, particularly for analysis and treatment of production errors.

Theoretically, an attempt has been made to extrapolate from M.T for the aphasic $S$ as it was originally developed to explain acquisition of phonology in the child. From the conclusions, possibly one may view the phonological breakdown in the following way: Where the child learns to inhibit natural segments and processes in the acquisition of his system, the aphasic adult fails to suppress the more natural processes as a result of neurological disruption. This may be viewed as 'disinhibition' or 'release phenomenon'. In a sense, this may be associated with the regression hypothesis proposed by Jakobson, ${ }^{16}$ and Spreen. ${ }^{30}$ However, it must be stressed that this is only seen in terms of broad phonological processes and general trends, rather than specific phoneme production. The applicability of natural phonology to aphasia incidentally bears some relation to an early theorist, Pick, who explained various speech disturbances on the basis of a 'disinhibition principle'. The writer suggested an alternative term to describe the phonological impairment in this adult aphasic S, namely: "Phonological Disinhibition". The word 'disinhibition' was used as it relates to the theory of Natural Phonology, but is quite distinct from that used by Luria. ${ }^{2 !}$

An $\mathrm{m} / \mathrm{u}$ analysis may be a useful tool for an in-depth phonological analysis, and may indeed supplement existing standardized tests. The implications extend outside clusters into all aspects of phonological impairment. It 
may facilitate an analysis in terms of $(\mathrm{m})$ and $(\mathrm{u})$ segments, graded on a continuum of relative complexity values. Phonological errors are assessed within a contextual framework, thus encouraging a certain amount of flexibility in relation to different phonemic environments. The relative complexity values facilitate the hierarchical arrangement of speech sounds and clusters, on which therapy can be based. It is essential to teach phonemes within a contrastive framework, yet defined within a scale of complexity as postulated in M.T. ${ }^{21}$ An assessment of natural phonological processes as outlined in Table VI, may provide an understanding of the 'system' and rules governing the error patterns of an individual patient. Central to the concept of 'naturalness' is the discoverable "path" from input to output, within complex sound changes." For example, in cluster reduction, D.F. theory would require a direct 'jump' from $\mathrm{pr} \rightarrow \mathrm{p}$, whereas M.T provides an explanation for the entire process, possibly from $\mathrm{pr} \rightarrow \mathrm{pl} \rightarrow \mathrm{p}$ in terms of complexity values. Markedness Theory thus seems to provide the intermediate steps necessary for prediction of error patterns or vulnerability of a particular phoneme to change; direction of change, evaluation of progress and accurate planning of steps towards rehabilitation.

With validation from further research, this approach might prove to be useful in the analysis and treatment of other phonological impairments.

\section{REFERENCES}

1. Blumstein, S.E. (1973): A Phonological Investigation of Aphasic Speech. Brown University and Aphasia Research Centre, Boston. Mouton, The Hague.

2. Cairns, C.E. (1969): Markedness, Neutralization, and Universal Redundancy Rules. Language., 45, 863-885.

3. Cairns, H.S. (1975): Phonetic feature Theory: The Linguist, the Speech Scientist and the Speech Pathologist. J.Comm. Dis., 8, 157170.

4. Chomsky, N., and Halle, M. (1968): The Sound Pattern of English. New York, Harper and Row.

5. Critchley, M. (1952): Articulatory Defects in Aphasia. J. Laryngol. Otol., 66, 1-17.

6. Darden, B.J. (1974): Introduction, In Natural Phonology - Papers from the Parasession on Natural Phonology, Chicago Linguistic Society. April 18th.

7. Deal, J.L., and Darley, F.L. (1972): The influence of linguistic and situational variables on Phonemic accuracy in apraxia of speech. $J$. Speech Hear. Res., 15(3), 639-653.

8. De Renzi, E., and Vignolo, L.A. (1966): Oral apraxia and aphasia. Cortex, 2, 50-73.

9. Fry, D.B. (1959): Phonemic substitutions in an aphasic patient. Lang Speech, 2, 52-61.

10. Goldman, R., and Fristoe, M.S. (1969): Goldman-Fristoe test of Articulation. American Guidance Service, Inc., Minnesota. 
11. Goldman, R., Fristoe, M.S., and Woodcock, R.W. (1970): GoldmanFristoe Test of Auditory Discrimination. American Guidance Service, Inc., Minnesota.

12. Goodglass, H., and.Kaplan, E. (1972): The assessment of aphasia and related disorders. Buston Veterans Administration Hospital and Aphasia Research Centre, Department of Neurology, Boston University.

13. Hatfield, F.M., and Walton, K. (1975): Phonological Patterns in a Case of Aphasia. Lang. and Speech., 18, 341-357.

14. Hyman, L.M. (1975): Phonology: Theory and Analysis. Holt, Rinehart and Winston, New Work U.S.A.

15. Ingram, D. (1976): Phonological Disability in Children. Studies in Language Rehabilitation and Remediation 2. Department of Linguistics, University of British Columbia.

16. Jacobson, R. (1968): Child Language, aphasia and phonological universals. Mouton, N.V. The Hague.

17. Johns, D.F., and Darley, F.L. (1970): Phonemic Variability in apraxia of speech. J. Speech. Hear. Res., 13, 556-583.

18. Johnson, W., Darley, F.L., and Sprietersbach, D.C. (1963): Diagnostic methods in speech Pathology. New York: Harper and Row.

19. Kagan, A. (1976): A Linguistic analysis of Expressive and Receptive Phonological Difficulties in Apraxia, and its Relevance to Therapy: A Case Study. Unpublished Research Report, Department of Speech Pathology and Audiology, University of the Witwatersrand, Johannesburg.

20. La Pointe, L.L. and Johns, D.F. (1975): Some Phonemic Characteristics in apraxia of speech.J.Comm. Dis., 8, 259-269.

21. Luria, A.R. (1970): Traumatic Aphasia, its Syndromes, Psychology and Treatment. Mouton, The Hague.

22. Martin, A.D. (1974): Some objections to the term apraxia of speech. J. Speech Hear. Dis., 39(1), 53-64.

23. Martin, A.D., Wasserman, N.H., Gilden, L., Gerstman, L. and West, J.A. (1975): A process model of repetition in aphasia: An Investigation of Phonological and Morphological Interactions in Aphasic Error Performance. Brain and Lang., 2, 434-450.

24. Mc Reynold, L.V., Engmann, D., and Dimmitt, K., (1974): Markedness Theory and Articulation Errors. J. Speech, Hear. Dis., 39(1), 93-103.

25. Menyuk, P. (1968): The role of Distinctive Features in Children's acquisition of Phonology. J. Speech, Hear. Res., 11, 138-146.

26. Olmsted, D.L. (1971): Out of the mouth of Babes. Earliest stages in Language Learning. Mouton and Co. N.V., The Hague.

27. Rosenbek, J.C., Wertz, R.T., and Darley, F.L. (1973): Oral Sensation and Perception in Apraxia of Speech. J. Speech. Hear. Res., 16, 2235.

28. Sarno, M.T., and Levita, E. (1971): Natural Course of Recovery in severe Aphasia. Arch. of Phys. med. and Rehab., 52, 175-178. 
29. Shankweiler, D., and Harris, K.S. (1966): An Experimental Approach to the problem of Articulation in Aphasia. Cortex:, 11, 277-292.

30. Spreen, O. (1968): Psycholinguistic aspects of Aphasia. J. Speech. Hear. Res., 11(3), 467-480.

31. Standel, J., Gardner, J., and Hannah, E.P. (1974): Distinctive Feature Analysis. Chap. 7 in Applied Linguistic Analysis Hannah, E.P. (Ed.), Joyce Publications, California.

32. Stanley, R. (1967): Redundancy Rules in Phonology. Language., 43, 393-436.

33. Trost, J., and Canter C.J. (1974): Apraxia of Speech in Patients with Broca's Aphasia: A study of Phonemic Production Accuracy and Error Pattern. Brain and Lang., 1, 63-79.

34. Walsh, H. (1974): On certain practical inadequacies of Distinctive Feature Systems. J. Speech Hear. Dis., 39(1), 32-43.

\title{
CHROMA/SONY/CCTV
}

\author{
DO YOU USE VIDEO \\ EQUIPMENT IN THERAPY?
}

Chroma provides a service of hire and sales, of the total range of Sony Video and Audio Equipment.

\section{CHROMA}

P.O. Box 31483

Braamfontein 2017

Johannesburg

Tel. 46-1750

The South African Journal of Communication Disorders, Vol. 25, 1978 


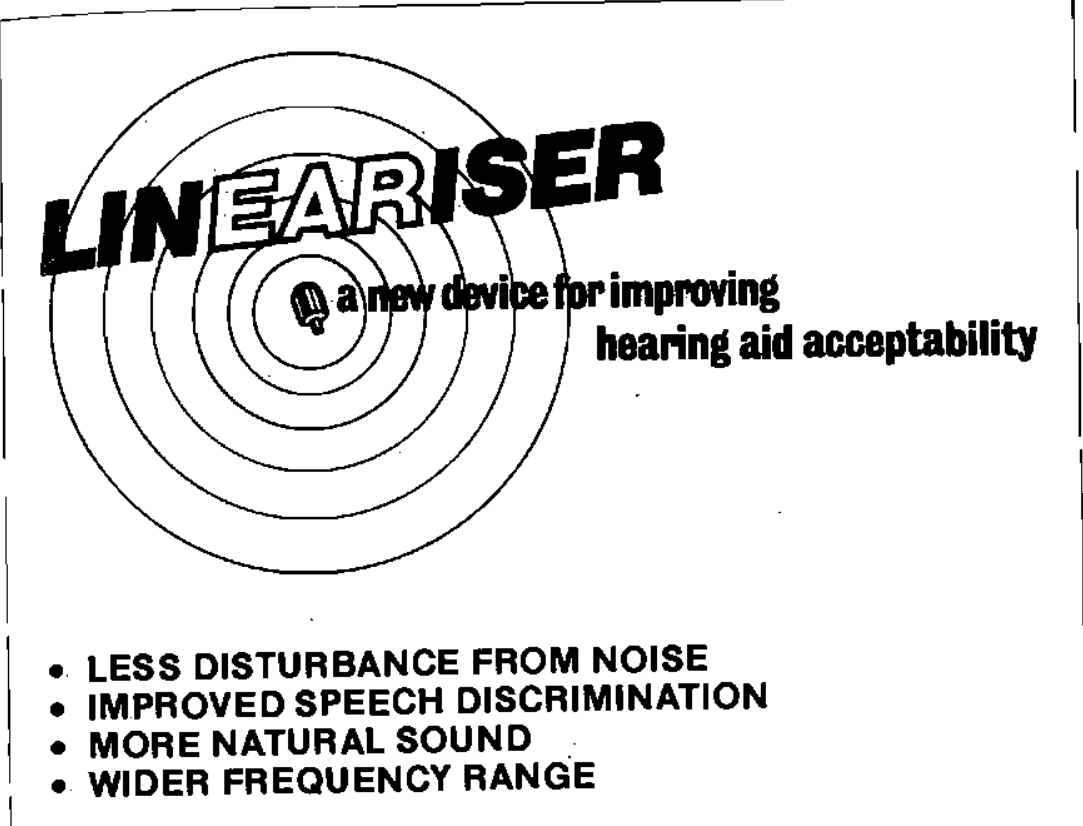

The Lineariser is a tiny acoustic device which eliminates the worst effects of resonance caused by the sound tube of behindthe-ear hearing aids. The Lineariser is fitted on the top of the earhook and can be attached to almost any hearing aid in a few seconds.

Approximately $90 \%$ of hearing aid users report an immediate improvement with the Lineariser fitted to the hearing aid. In many cases successful results are achieved with the Lineariser where people have not previously been able to use a hearing aid.

\author{
AVAILABLE FROM: \\ Acoustimed (Pty) Ltd \\ 515 Louis Pastour Building \\ Schoeman St. Pretoria \\ Tel: 23202 (Pretoria)
}

HEARING SERVICES

315 Bosman Buildings

Cor. Eloff and Bree Streets

Johannesburg

Tel: 372978
MANUFACTURED BY:

Acoustimed (Pty) Ltd

302 Sandown Centre

Maud Street, Sandown

TelL 784-0152

\title{
AGENTS THROUGHOUT SOUTH AFRICA
}

